\title{
Synthesis of single-walled carbon nanotubes by the pyrolysis of a compression activated iron(II) phthalocyanine/phthalocyanine metal-free derivative/ferric acetate mixture
}

\author{
TAWANDA MUGADZA ${ }^{\mathrm{a}, \mathrm{b}, *}$, EDITH ANTUNES $^{\mathrm{b}}$ and TEBELLO NYOKONG ${ }^{\mathrm{b}}$ \\ a Department of Chemical Technology, Midlands State University, Bag 9055, Gweru, Zimbabwe \\ ${ }^{\mathrm{b}}$ Chemistry Department, Rhodes University, Grahamstown 6140, South Africa \\ e-mail:mugadzat@gmail.com
}

MS received 6 November 2014; revised 9 March 2015; accepted 11 March 2015

\begin{abstract}
This paper reports on the synthesis of single walled carbon nanotubes (SWCNTs) from an activated mixture of iron (II) phthalocyanine, its metal-free derivative and ferric acetate. The powdered mixture was activated by compression into a tablet by applying a force of $300 \mathrm{kN}$, followed by re-grinding into powder and heating it to high temperatures $\left(1000^{\circ} \mathrm{C}\right)$. The activation by compression resulted in more than $50 \%$ debundling of SWCNTs as judged by transition electron microscopy. Acid functionalization of the SWCNTs was confirmed by the increase in the D:G ratio from 0.56 to 0.87 in the Raman spectra and the observation of an average of one carboxylic acid group per 13 carbon atoms from thermogravimetric analysis (TGA). TGA also showed that the initial decomposition temperatures for the activated and non-activated mixtures to be $205^{\circ} \mathrm{C}$ and $245^{\circ} \mathrm{C}$, respectively. Hence, activation leads to the lowering of the pyrolysis temperature of the phthalocyanines. X-ray diffraction, electronic absorption and Fourier transform infrared spectra were also employed to characterize the SWCNT.
\end{abstract}

Keywords. Carbon nanotubes; iron(II) phthalocyanine; iron(III) acetate.

\section{Introduction}

Single wall carbon nanotubes (SWCNTs) was first reported in 1993 in two independent reports, ${ }^{1,2}$ though a similar structure was observed in 1976 by Oberlin et al. ${ }^{3}$ Arc-discharge, ${ }^{1,2}$ laser ablation, ${ }^{4}$ pyrolysis of iron (II) phthalocyanines ${ }^{5-8}$ and catalytic chemical vapor deposition $(\mathrm{CVD})^{9-14}$ methods have been employed in the synthesis of carbon nanotubes (CNTs). The limitation of these synthetic approaches is the production of impurities like fullerenes, amorphous carbon, graphite particles and graphitic polyhedrons with enclosed metal particles and metallic clusters. ${ }^{15}$

Synthesis of carbon nanotubes from metal phthalocyanines $\left(\mathrm{MPc}, \mathrm{M}=\mathrm{Fe}, \mathrm{Co}, \mathrm{Ni} ; \mathrm{Pc}=\mathrm{C}_{32} \mathrm{H}_{16} \mathrm{~N}_{8}\right.$ ) has been reported to be simple and cheap ${ }^{16-20}$ with a potential for large scale production. ${ }^{17-20}$ Though simple, the major problem is in controlling the diameter size. Harutyunyan et al. addressed this by diluting iron phthalocyanines $(\mathrm{FePc})$ with various amounts of metalfree phthalocyanine. ${ }^{21}$ In the presence of excess amounts of the latter, there might be higher chance of forming multi-walled carbon nanotubes (MWCNTs) as opposed to single walled carbon nanotubes (SWCNTs), which

\footnotetext{
*For correspondence
}

was usually formed in the presence of a metal catalyst. Chen et al. reported ball milling for $100 \mathrm{~h}$ in an argon atmosphere at a pressure of $300 \mathrm{kPa}^{22-24}$ as a way of activating precursors of CNTs, such as phthalocyanines. ${ }^{22}$

This work reports on a much simpler, more effective and very rapid method for the activation of a mixture of iron(II) phthalocyanine (FePc) and metal-free phthalocyanine $\left(\mathrm{H}_{2} \mathrm{Pc}\right)$ in the presence of ferric acetate for the in situ synthesis of SWCNTs. $\mathrm{H}_{2} \mathrm{Pc}$ and FePc serve as sources of carbon. Ferric acetate in the mixture provides the iron particles that are required for the initiation of SWCNT growth. By providing more nucleating sites, the iron particles promote the formation of SWCNTs rather than MWCNTs. The mixture is activated by first applying a compression force to give a tablet, followed by regrinding and heating. The activation process lowers the temperature required for the formation of CNTs. To our knowledge, this mode of activation is being reported for the first time.

The major thermal decomposition of FePc begins at around $275^{\circ} \mathrm{C}^{25}$ and coincides with the decomposition of ferric acetate at around $278-328^{\circ} \mathrm{C} .{ }^{26}$ These similar decomposition temperatures serve as a basis for the choice of ferric acetate as an aid to the synthesis of CNTs. At this decomposition temperature ferric acetate provides the much needed iron seeds for the initial 
growth of CNTs. Metal-free phthalocyanine begins decomposition at around $500^{\circ} \mathrm{C}^{25}$ and this ensures continuity in the growth of CNTs well after all the FePc has decomposed. It has also been reported that $\mathrm{H}_{2} \mathrm{Pc}$ controls diameter size. ${ }^{21}$ In the current work, Ar gas was used to provide an inert atmosphere during the purging and cooling process steps, while hydrogen gas moderates the decomposition of the hydrocarbon. ${ }^{14}$ The successful synthesis of CNTs by this approach was elucidated by transmission electron microscopy (TEM), Fourier Transform infrared (FTIR), x-ray diffraction (XRD) and Raman ${ }^{27,28}$ spectroscopies and thermogravimetric analysis (TGA). The electrocatalytic nature of these SWCNTs was ascertained through the observed reduced overpotentials relative to the bare glassy carbon electrode (GCE) using amitrole as an electroactive analyte of interest.

\section{Experimental}

\subsection{Materials and Methods}

Metal-free phthalocyanine $98 \%, \mathrm{C}_{32} \mathrm{H}_{18} \mathrm{~N}_{8}$ (molar mass $=514.55$, M.p. $=300^{\circ} \mathrm{C}$ ), single walled carbon nanotubes (SWCNT, 0.7-1.2 nm in diameter and 2-20 $\mu \mathrm{m}$ in length), dimethyl-formamide (DMF), potassium bromide and $\mathrm{Fe}\left(\mathrm{CH}_{3} \mathrm{COO}\right)_{3}$ were purchased from Aldrich while iron(II) phthalocyanine was synthesized using reported method. ${ }^{29}$ Dimethylformamide (DMF) was freshly distilled and dried before use. Aqueous solutions were prepared using Millipore water from Milli-Q Water Systems (Millipore Corp., Bedford, MA, USA, conductivity range $=0.055-0.294 \mu \mathrm{S} / \mathrm{cm})$. All other chemicals and reagents were of analytical grade and were used as received.

\subsection{Electrochemical methods}

Before use, the glassy carbon electrode (GCE) was polished on a Buehler-felt pad using alumina $(0.05 \mu \mathrm{m})$, and then washed with Millipore water, sonicated for 5 min in millipore water, washed again with millipore water and then with $\mathrm{pH} 4$ buffer solution. The GCE was modified with acid functionalized SWCNTs (SWCNT-COOH) that had initially been dispersed in DMF through ultrasonication for $1 \mathrm{~h}$ using the drop and dry method. The modified electrode was then rinsed in $\mathrm{pH} 4$ buffer solution before analysis. All solutions for voltammetric study were prepared in $\mathrm{pH} 4$ buffer. The $\left[\mathrm{Fe}(\mathrm{CN})_{6}\right]^{3-/ 4-}$ redox system in $0.1 \mathrm{M} \mathrm{KCl}$ was used as a redox probe for the electron transfer efficiency of the synthesized SWCNTs. Prior to the analyses all the solutions for voltammetry were purged with argon gas to drive out oxygen and an atmosphere of argon was maintained throughout the analyses. Before use for analyses, the modified electrode was scanned between 0.0 $\mathrm{V}$ and $1.0 \mathrm{~V}$ (versus $\mathrm{Ag} \mid \mathrm{AgCl} 3 \mathrm{M} \mathrm{KCl}$ ) in $\mathrm{pH} 4$ buffer solution to obtain stable cyclic voltammograms.

\subsection{Equipments}

Electrochemical data (cyclic voltammetry) was recorded using a Princeton Applied Research potentiostat/galvanostat Model 264A. A three electrode electrochemical cell composed of GCE $\left(0.071 \mathrm{~cm}^{2}\right)$ was employed as a working electrode, platinum wire $(\mathrm{Pt})$ as a counter electrode and a silverlsilver chloride wire $(\mathrm{Agl} \mathrm{AgCl})$ was used as a pseudo reference electrode.

Shimadzu UV-2550 spectrophotometer and Bruker Vertex 70-Ram II spectrometer (equipped with a 1064 $\mathrm{nm} \mathrm{Nd}$ :YAG laser and a liquid nitrogen cooled germanium detector) were used to collect UV-vis and Raman data, respectively. FTIR spectra were collected with the Perkin-Elmer Spectrum 100 FT-IR spectrometer fitted with a universal ATR sampling accessory. XRD patterns were recorded on a Bruker D8 Discover, equipped with a PSD LynxEye detector, using $\mathrm{Cu}-\mathrm{K}_{\alpha}$ radiation $(\lambda=$ $1.5405 \AA$, nickel filter). Samples were placed on a zero background (511) silicon wafer embedded in a generic sample holder and data recorded within the range $2 \theta=$ $15^{\circ}$ to $60^{\circ}$, scanning at $1^{\circ} \mathrm{min}^{-1}$ with a filter timeconstant of $2.0 \mathrm{~s}$ per step at room temperature. A slit width of $6.0 \mathrm{~mm}$ was used in the measurements. X-ray diffraction data were fitted using Eva (evaluation curve fitting) software, while analysis of data was done using International Center Diffraction Data (ICDD) database. The Raman, FTIR and XRD spectral data for the raw SWCNTs and carboxylic acid functionalized SWCNTs (SWCNT-COOH) were acquired in their powder forms.

TEM images were obtained using a JEOL JEM 1210 transmission electron microscope at $100 \mathrm{kV}$ accelerating voltage. The $\mathrm{FePc} / \mathrm{H}_{2} \mathrm{Pc} / \mathrm{Fe}\left(\mathrm{CH}_{3} \mathrm{COO}\right)_{3}$ mixture was activated by using a $300 \mathrm{kN}$ force Press (M-30 from the Research and Industrial Instruments Company, United Kingdom) and a Carbolite Furnace, Zenith 681 capable of operating in excess of $1000^{\circ} \mathrm{C}$ was used in the formation of carbon nanotubes. The Perkin-Elmer Thermogravimetric Analyzer equipped with Pyris software was used for thermogravimetric analysis.

\subsection{Synthesis of CNTs}

FePc, $\mathrm{H}_{2} \mathrm{Pc}$ and $\mathrm{Fe}\left(\mathrm{CH}_{3} \mathrm{COO}\right)_{3}$ were thoroughly ground together in the ratio of 1:1:2 using a pestle and mortar. 
The powdered mixture was compressed into activated tablets in a tablet- making accessory by applying a maximum force of $300 \mathrm{kN}$. The activated tablets were re-ground into powder using a pestle and mortar and placed in a ceramic boat and then inserted into a quartz heating tube. The quartz tube and its contents were placed into a furnace and the temperature raised to $1000^{\circ} \mathrm{C}$ in the presence of an argon/hydrogen atmosphere flowing at a rate of $40 \mathrm{~cm}^{3} / \mathrm{min}$ for $1 \mathrm{~h}$, after which the furnace was allowed to cool. The synthesized SWCNTs (raw SWCNTs) were subsequently removed from the furnace. Such SWCNTs normally contain impurities like carbonaceous materials (e.g., amorphous carbon, fullerenes and carbon nanoparticles) and metal catalyst particles.

\subsection{Purification of SWCNTs}

The raw SWCNTs were vigorously stirred in toluene for about $2 \mathrm{~h}$ to remove any fullerenes ${ }^{13}$ that may be present. Amorphous carbon and carbon nanoparticles (CNPs) were removed through oxidation of SWCNT in a 3:1 mixture of concentrated acids $\left(\mathrm{H}_{2} \mathrm{SO}_{4}: \mathrm{HNO}_{3}\right)$ for $2 \mathrm{~h},{ }^{30}$ leaving behind relatively pure SWCNTs. ${ }^{13}$ This chemical purification process is selective and removes carbonaceous impurities due to their dangling bonds and structural defects ${ }^{13}$ with the only limitation being the opening of the CNT ends and the introduction of oxygenated terminals. ${ }^{31}$ These acid purified SWCNTs were then subjected to low-speed centrifugation in order to remove any unoxidised amorphous carbon, leaving behind SWCNTs and CNPs, in the sediment. The remaining mixture was then exposed to high-speed centrifugation that settled CNPs leaving behind SWCNTs suspended in aqueous media. ${ }^{13}$ Chemical oxidation of the SWCNTs and centrifugation ensured effective removal of most impurities. The purified SWCNTs were centrifuged and washed with millipore water several times until a $\mathrm{pH}$ of 5 was attained, to give SWCNT-COOH. The SWCNT-COOH were dried in oven at $110^{\circ} \mathrm{C}$ for $12 \mathrm{~h} .{ }^{30}$ The SWCNT-COOH were analyzed through different spectroscopic and microscopic techniques.

\section{Results and Discussion}

Activation of the metal-free phthalocyanine/iron(II) phthalocyanine/ferric acetate mixture was achieved by applying a force of $300 \mathrm{kN}$ to give an activated tablet that is later ground into a fine powder. This activation method proved to be fast, simple and effective in encouraging the formation and reduction of CNTs diameter sizes without any ball milling of the mixture at very high pressures as reported elsewhere. ${ }^{22-24}$ Characterisation was done through a variety of techniques for no single analytical tool will suffice. ${ }^{32}$ For instance FTIR is not very informative when it comes to the identification of organic groups with the exception of carboxylic acids. ${ }^{33}$

\subsection{Transition Electron Microscopy (TEM)}

TEM provides qualitative information on defects, and on amorphous carbon and fullerenes that are adsorbed onto the CNTs walls ${ }^{13}$ with the limitation being its failure to give quantitative information. ${ }^{34}$ It is also possible to estimate both the internal and external diameters of carbon nanotubes using TEM. ${ }^{35}$

The TEM images in figure 1 shows globules of carbon without activation of the mixture (after acid purification, figure 1a), CNT bundles after activation by compression (not acid treated, figure 1b), incompletely unbundled, acid treated CNT (figure 1c) and unbundled, acid treated CNTs (figure 1d), all ultrasonically dispersed in DMF and dropped onto a copper grid. However, it has been mentioned that ultrasonication may destroy the structure of the tube. ${ }^{36}$ It is clear that without activation by compression, CNTs are not formed (figure 1a) and this therefore highlights the importance of the activation step in reducing the inter-atomic distances and thereby encouraging the formation of CNTs (figure 1b-d). Activation produces CNTs which are less bundled, figure $1 \mathrm{~b}$, and inadequate acid treatment does not unbundle CNTs completely, figure 1c. Adequate acid purification removed most of the oxidisable impurities, thus exposing the CNT fine structures, figure 1d. Such structures have been observed before. ${ }^{37}$ The dark spots observed in figure $1 \mathrm{~d}$ could be remnant metallic (iron) clusters after acid treatment. ${ }^{38}$ The TEM picture (figure 1d) confirms that the SWCNTs were successfully synthesized since the diameters of SWCNTs are normally within the range of $1-3 \mathrm{~nm} .{ }^{39} \mathrm{CNTs}$ with diameters greater than $3 \mathrm{~nm}$ are referred to as large diameter SWCNTs. ${ }^{39}$ The use of a catalyst such as Fe usually results in SWCNT, but MWCNT can form depending on the ratio of catalyst to carbon and FePc to $\mathrm{H}_{2} \mathrm{Pc}^{21}$ The TEM images show diameters that are of varied sizes, from $2.56 \mathrm{~nm}$ to $10.03 \mathrm{~nm}$ and are several nanometers long. This shows that the synthesized CNTs are single walled and the observed larger diameter could be due to aggregated SWCNTs. Normally for the non-activated FePc, the SWCNT bundle diameters are in the range $40-100 \mathrm{~nm},{ }^{40}$ but in this work diameter sizes were reduced to less than $20 \mathrm{~nm}$, showing, 

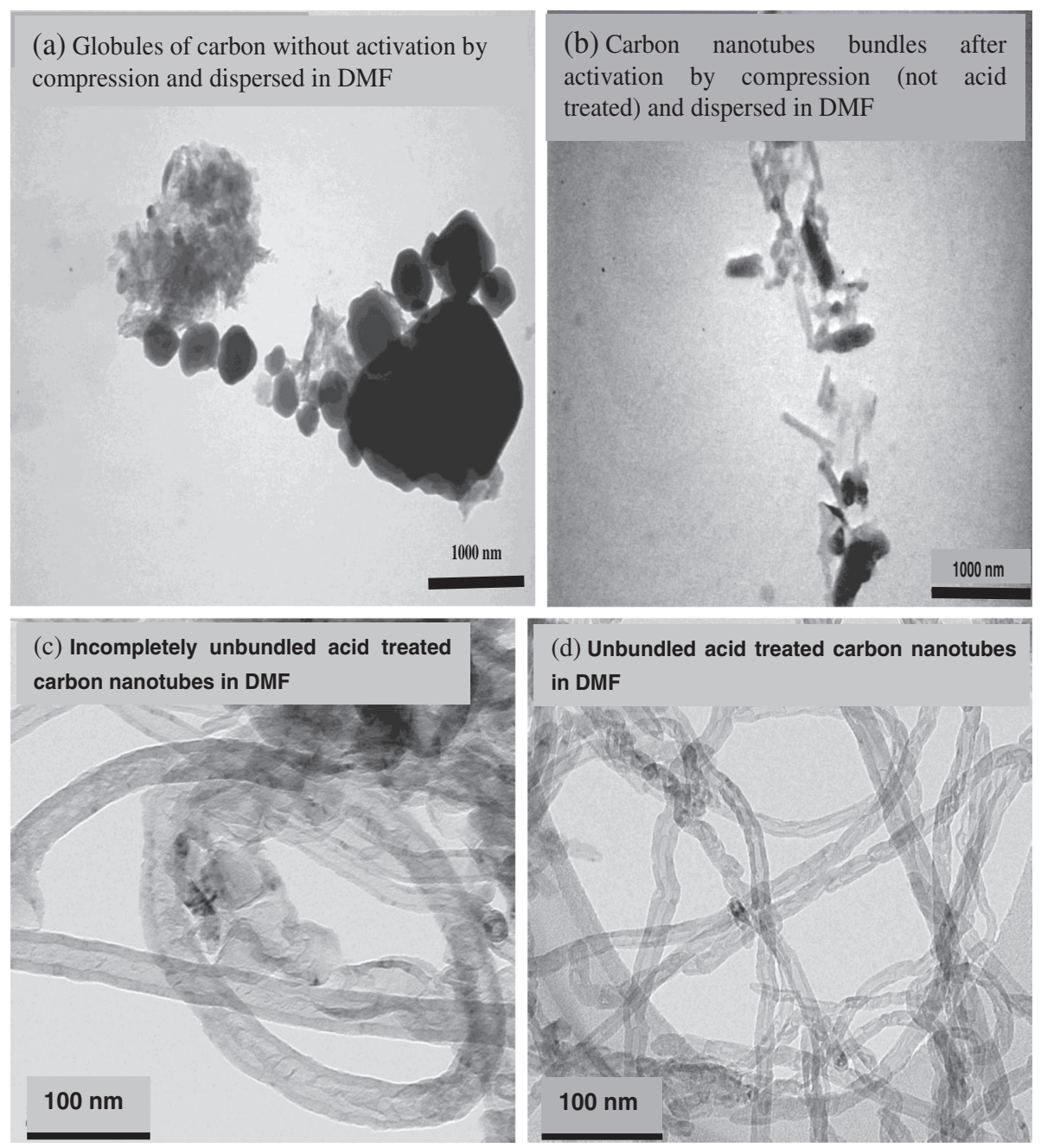

Figure 1. TEM images of (a) globules of carbon without activation by compression, (b) carbon nanotube bundles after activation by compression (not acid treated), (c) incompletely unbundled, acid treated carbon nanotubes and (d) unbundled, acid treated carbon nanotubes.

additionally, the effectiveness of the activation process, thus activation reduces bundling by at least $50 \%$.

\subsection{UV-vis Spectroscopy}

UV-vis spectroscopy is a rapid and convenient qualitative technique to estimate the relative purity of bulk SWCNTs. ${ }^{34}$ The absorption spectra for both the synthesized SWCNTs (figure 2a) and the further acid purified SWCNTs (SWCNT-COOH, figure 2b) are relatively smooth. The SWCNT-COOH have reduced absorbance due to (figure 2b) further acid treatment as observed elsewhere. ${ }^{41}$ Normally raw CNTs absorption spectra are associated with van Hove singularities of metallic and semiconducting nanotubes that are attributed to their band-gap transitions whose widths reflect the overlap of features from CNTs having different diameters and chiral indices. ${ }^{42}$ The absence of

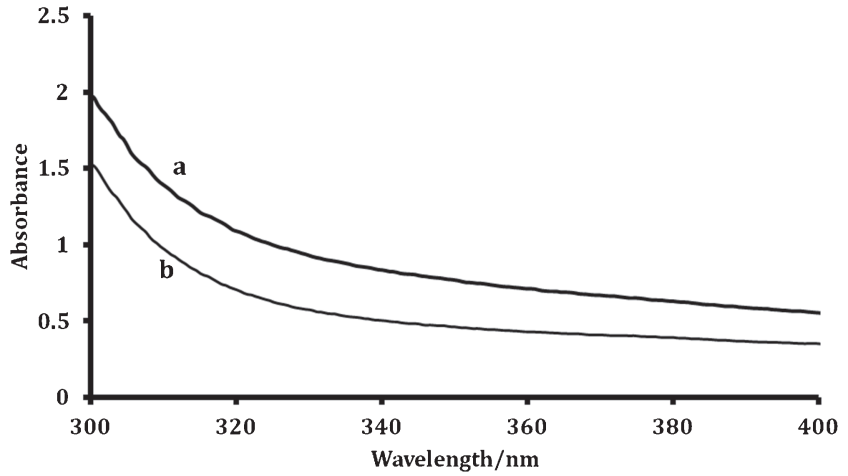

Figure 2. UV-vis spectra for (a) synthesized SWCNTs and (b) SWCNT-COOH, both dispersed in DMF.

van Hove singularities in the synthesized SWCNTs (figures $2 \mathrm{a}$ and $2 \mathrm{~b}$ ) indicate that the CNTs were relatively pure. ${ }^{43,44}$ 


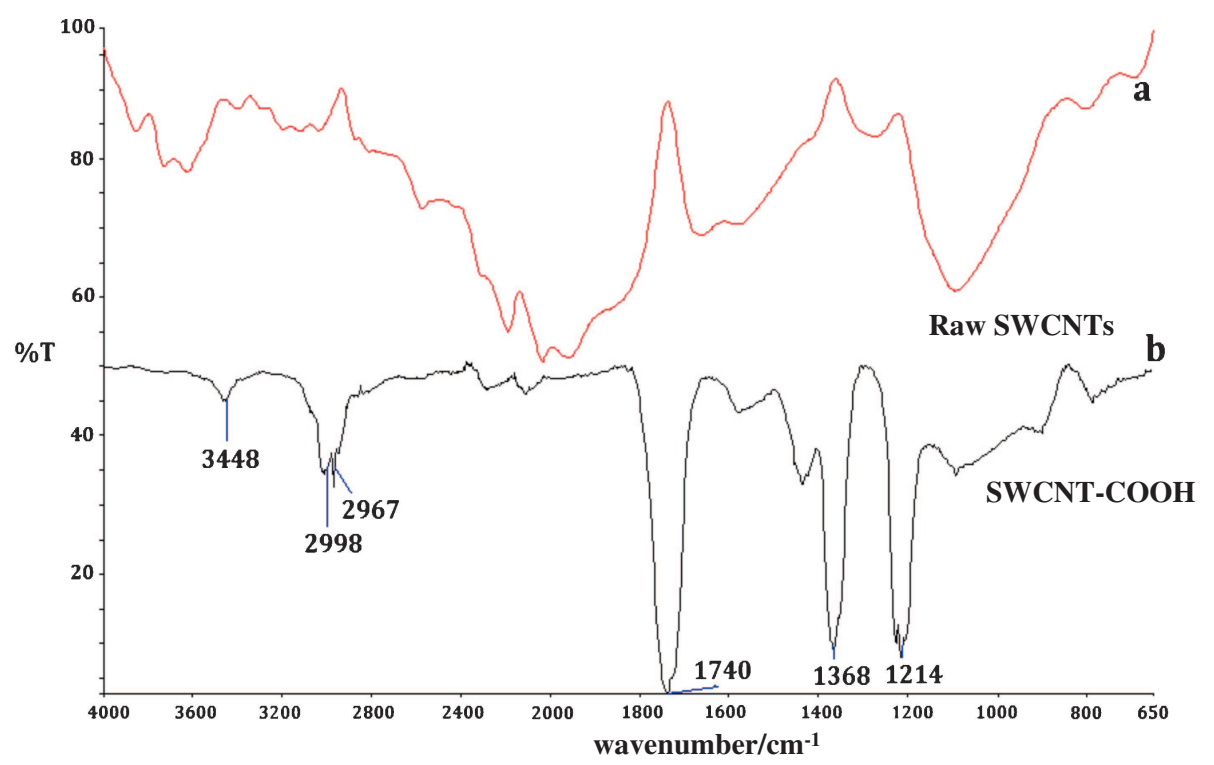

Figure 3. FTIR spectra for (a) synthesized SWCNTs and (b) SWCNT-COOH.

\subsection{Infrared Spectroscopy}

Figure 3 shows the FTIR spectra for the raw SWCNTs and SWCNT-COOH. Both the raw and the acid functionalized SWCNTs were heated for $24 \mathrm{~h}$ at $100^{\circ} \mathrm{C}$ to drive out all the water that may be present, ${ }^{45}$ then mixed with potassium bromide and pressed into pellets. ${ }^{45}$ The pellets were further dried by heating them above the boiling temperature of water. Synthesized SWCNTs show ill-defined absorption bands which improved with acid purification as observed elsewhere. ${ }^{46}$ Well defined peaks at 3448, 2967, 2998, 1740, 1368 and $1214 \mathrm{~cm}^{-1}$ are attributed to the O$\mathrm{H}, \mathrm{C}-\mathrm{H}, \mathrm{C}=\mathrm{O}, \mathrm{C}-\mathrm{N}$ and $\mathrm{C}-\mathrm{O}$ stretches, respectively, as has been reported before. ${ }^{46,47}$ The presence of well defined bands in purified SWCNTs confirms their successful synthesis and oxidation of the $s p^{2}$ carbon atoms to carboxylic acid groups.

\subsection{Thermogravimetric analysis}

Thermogravimetric analysis (TGA) showed quantitative and qualitative structural and behavioral differences between the $\mathrm{H}_{2} \mathrm{Pc}, \mathrm{FePc}, \mathrm{Fe}\left(\mathrm{CH}_{3} \mathrm{COO}\right)_{3}$, non-activated and activated $\left(\mathrm{H}_{2} \mathrm{Pc} / \mathrm{FePc} / \mathrm{Fe}\left(\mathrm{CH}_{3} \mathrm{COO}\right)_{3}\right)$ mixture. Figure $4 \mathrm{a}$ compares the TGA traces for $\mathrm{H}_{2} \mathrm{Pc}, \mathrm{FePc}$, non-activated $\mathrm{Pc}$ mixture, activated $\mathrm{Pc}$ mixture and $\mathrm{Fe}\left(\mathrm{CH}_{3} \mathrm{COO}\right)_{3}$. Derivative TGA was used to deduce the initial decomposition temperatures for all the materials under study. Thermal decomposition of the FePc (figure 4a (iv)) begins at around $230^{\circ} \mathrm{C}$ as observed elsewhere, ${ }^{26}$ a temperature very close to where $\mathrm{Fe}$ $\left(\mathrm{CH}_{3} \mathrm{COO}\right)_{3}$ starts to decompose $\left(220^{\circ} \mathrm{C}\right)$, while the decomposition of the $\mathrm{H}_{2} \mathrm{Pc}$ begins at around $560^{\circ} \mathrm{C}$

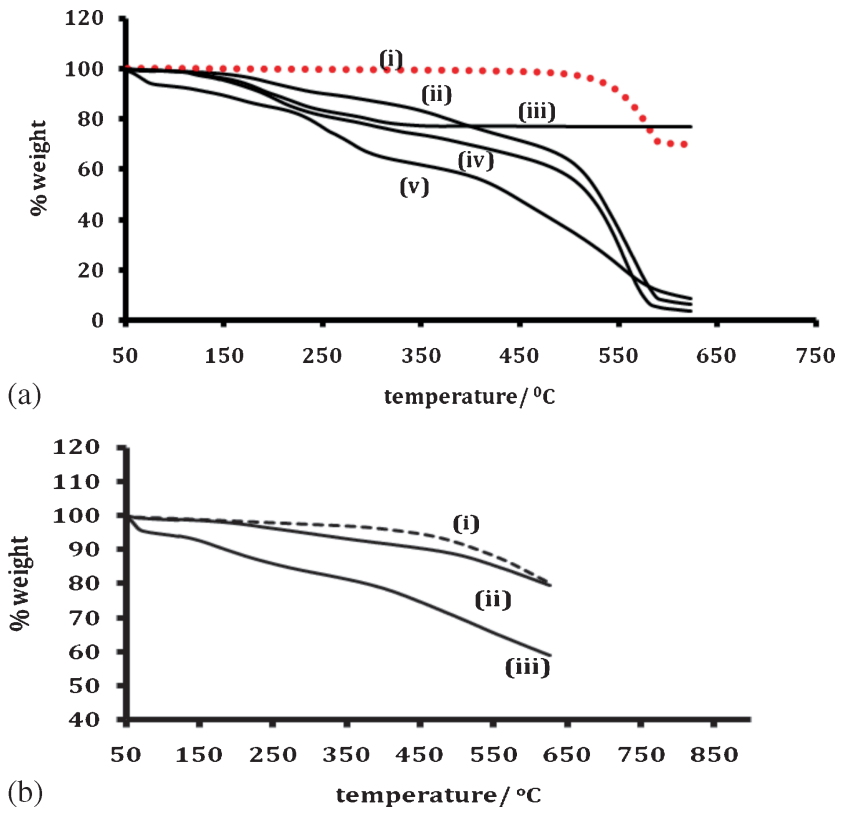

Figure 4. TGA of (a) (i) $\mathrm{H}_{2} \mathrm{Pc}$, (ii) non-activated $\mathrm{H}_{2} \mathrm{Pc}$ / $\mathrm{FePc} / \mathrm{Fe}\left(\mathrm{CH}_{3} \mathrm{COO}\right)_{3}$ mixture, (iii) $\mathrm{Fe}\left(\mathrm{CH}_{3} \mathrm{COO}\right)_{3}$, (iv) $\mathrm{FePc}$ and (v) activated $\mathrm{H}_{2} \mathrm{Pc} / \mathrm{FePc} / \mathrm{Fe}\left(\mathrm{CH}_{3} \mathrm{COO}\right)_{3}$ mixture. (b) (i) raw SWCNTs (purchased) (ii) synthesized SWCNT and (iii) SWCNT-COOH at a heating rate of $10^{\circ} \mathrm{C} / \mathrm{min}$ under nitrogen.

(figure $4 \mathrm{a}(\mathrm{i})$ ). In the non-activated $\mathrm{H}_{2} \mathrm{Pc} / \mathrm{FePc} / \mathrm{Fe}\left(\mathrm{CH}_{3}\right.$ $\mathrm{COO})_{3}$ mixture, the decomposition of $\mathrm{Fe}\left(\mathrm{CH}_{3} \mathrm{COO}\right)_{3}$ and $\mathrm{FePc}$ begins in the temperature range $220-230^{\circ} \mathrm{C}$, in agreement with thermogram (iii) for $\mathrm{Fe}\left(\mathrm{CH}_{3} \mathrm{COO}\right)_{3}$ and (iv) for FePc. The decomposition of the activated mixture is initiated at a lower temperature compared to the non-activated mixture. This was confirmed by derivative TGA, which gave the initial decomposition 
temperatures for the activated and non-activated mixtures to be $205^{\circ} \mathrm{C}$ and $245^{\circ} \mathrm{C}$, respectively. It can be conclusively deduced from TGA studies that the compression method of activation is effective in imparting the necessary structural and behavioral changes that are required for the formation of CNTs from the mixture. This leads to the lowering of the decomposition temperatures in the activated mixture (as shown in figure 4a (v)) which in turn could lead to the lowering of the pyrolysis temperature of the Pcs.

Figure $4 \mathrm{~b}$ shows the thermograms obtained for raw SWCNTs (purchased), synthesized SWCNTs and acid treated SWCNT (SWCNT-COOH). Samples of $1.4 \mathrm{mg}$ each of raw SWCNTs (purchased), synthesized SWCNTs and SWCNT-COOH were heated under nitrogen from $50^{\circ} \mathrm{C}$ to $625^{\circ} \mathrm{C}$ at a heating rate of $10^{\circ} \mathrm{C} / \mathrm{min}$. The difference in the nature of the TGA profiles is an indication of their structural differences. Weight loss observed for the raw CNTs (purchased and synthesized) may be due to loss of water, but could also be due to the destruction of the residual amorphous carbon present in the carbon nanotubes. ${ }^{48}$ For SWCNT-COOH, further weight loss could be due the decomposition of the carboxylic acid group in addition to the loss of water and maybe some unoxidised amorphous carbon. TGA traces showed similar weight loss of $\sim 17.0 \%$ (at $625^{\circ} \mathrm{C}$ ) for both the purchased and synthesized SWCNTs and $39.1 \%$ for the SWCNT-COOH. A similar trend for SWCNT-COOH has been observed elsewhere. ${ }^{41}$ Similarities in the \% weight loss for the purchased and synthesized SWCNTs signify approximately equal amounts of amorphous carbon content. Having considered the weight loss due to adsorbed volatiles $(6.1 \%)$, the $\%$ loss due to amorphous carbon is $\sim 13.1 \%$, giving a purity of about $80.8 \%$ (as single walled carbon nanotubes) at $625^{\circ} \mathrm{C}$. Their quality is comparatively good relative to the Aldrich SWCNTs, whose carbon content as single walled carbon nanotube is estimated to be $82.5 \%$ at the same temperature. This is a crude estimate, based on the assumption that all impurities have

(a)
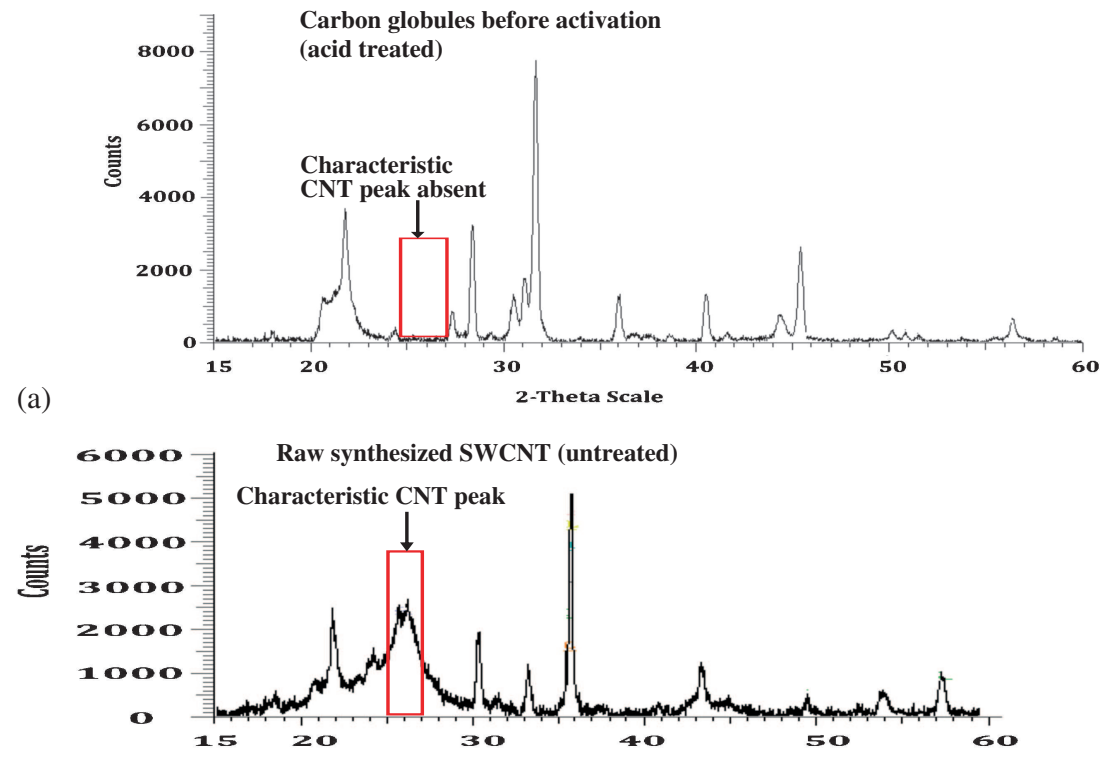

(b)
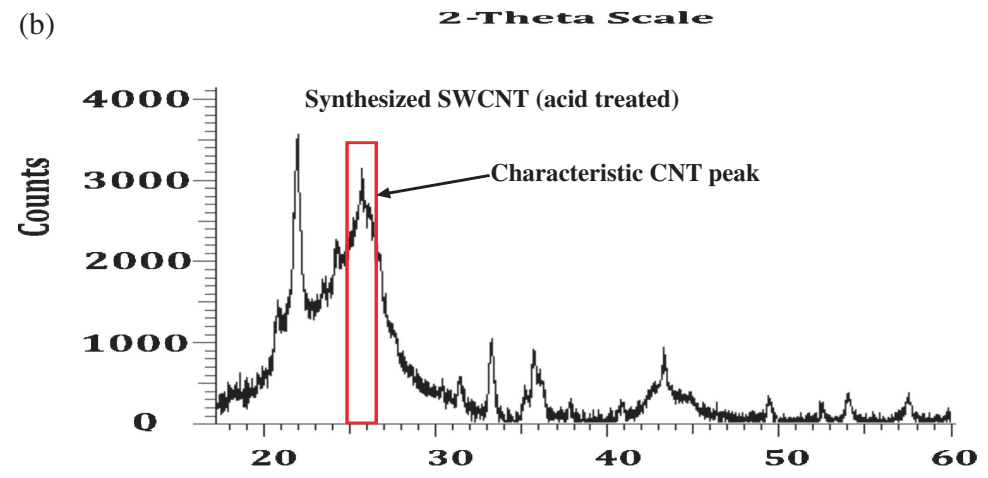

(c)

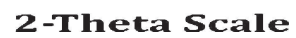

Figure 5. XRD spectra for the synthesized (a) carbon globules before activation (acid treated), (b) synthesized SWCNTs (not acid treated) and (c) synthesized SWCNTs (acid treated). 
been eliminated, though CNTs are known to contain some residual metallic clusters, irrespective of the acid purification. ${ }^{15}$

The extent of functionalization (conversion of $s p^{2}$ carbons to $s p^{3} \mathrm{COOH}$ groups) is expressed as the number of substituents per SWCNT carbon atoms. By applying the formula reported in the literature, ${ }^{49}$ the estimated weight loss due to the functionalization of SWCNT-COOH was $22.1 \%$ giving on average, one carboxylic group per 13 carbon atoms.

\subsection{X-ray diffraction spectroscopy}

$\mathrm{X}$-ray diffraction spectroscopy was used to ascertain the formation of CNTs and to examine the structural differences between the synthesized SWCNTs and SWCNT$\mathrm{COOH}$. Figure 5 shows the XRD spectra for carbon globules (figure 1a TEM image) that were formed without activation but acid treated (figure 5a), synthesized SWCNTs (figure 5b) and synthesized acid treated SWCNT (SWCNT-COOH, figure 5c). Table 1 lists the $2 \theta$-values, d-spacings and the peak intensities for the synthesized SWCNTs and SWCNT-COOH. The peaks at $2 \theta$ angles of $25.7^{\circ}, 43.4^{\circ}$ and $52.4^{\circ}$ in figure $5 \mathrm{c}$ (SWCNT-COOH) correspond to the graphite (002) dspacing of the SWCNTs, ${ }^{50-52}$ the (111) and (200) reflections of carbon, ${ }^{52}$ respectively. The peak due to graphite $\mathrm{d}$-spacing around $26^{\circ}$ is conspicuously absent in the carbon globules, figure 5a, a testimony to the importance of compressive activation in the CNT synthesis. It was only after activation that the graphite $002 \mathrm{~d}$-spacing (around $26^{\circ}$ ) was observed in raw synthesized SWCNTs. Functionalization of the synthesized SWCNTs to SWCNT-COOH increased the intensities of the first two peaks while the rest of the peaks decreased in intensities. Decreases and increases in peak intensities have been observed before and could be associated with the oxidizing nature of the $\mathrm{H}_{2} \mathrm{SO}_{4} / \mathrm{HNO}_{3}$ mixture. ${ }^{52}$ Peaks at $\sim 33^{\circ}, 36^{\circ}$ and $57.5^{\circ}$ have been observed elsewhere and assigned Miller indices, but their origin was not explained. ${ }^{48}$

\subsection{Raman spectroscopy}

Raman spectroscopy is a fast, convenient and nondestructive analytical technique and can be used to some extent to quantify the amount of impurities by using the ratio of $\mathrm{D} / \mathrm{G}$ bands under fixed laser power intensity. ${ }^{53}$ Literature has confirmed that though FTIR and Raman are complementary techniques the latter is more revealing. ${ }^{32}$ The appearance of D- and G-bands indicated the successful synthesis of SWCNTs, figure 6 . These spectra for the synthesized (figure 6a) and functionalized SWCNTs (figure 6b) were both observed at a laser intensity of $50 \mathrm{~mW}$. The D- and G- bands are at 1294 and $1587 \mathrm{~cm}^{-1}$ and at 1290 and $1583 \mathrm{~cm}^{-1}$ for the synthesized and acid functionalized SWCNTs, respectively. The peak at $1583 \mathrm{~cm}^{-1}$ in functionalized SWCNTs is a measure of the extent of graphitization. ${ }^{32}$ The ratios of $\mathrm{D} / \mathrm{G}$ peak intensities for the raw and functionalized SWCNTs are 0.63 and 1.10, respectively. In both

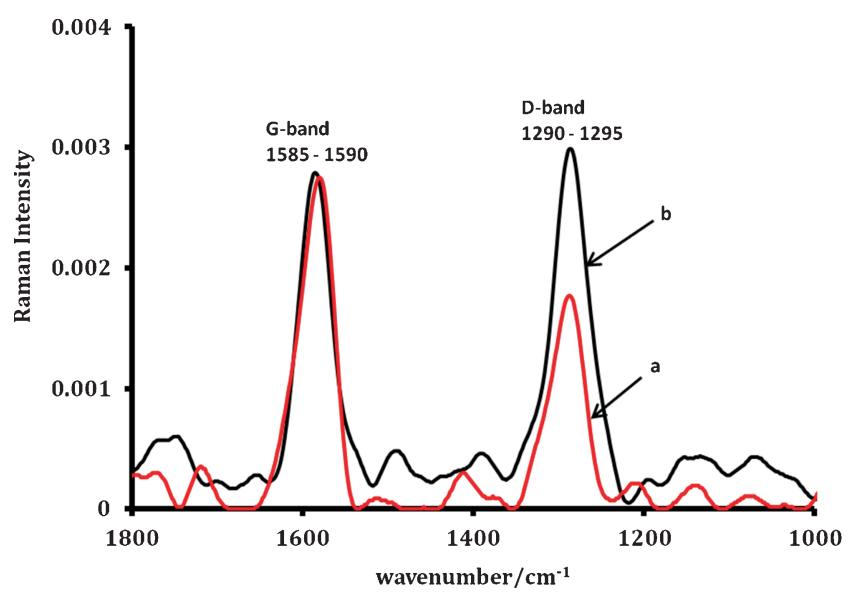

Figure 6. Raman spectra for (a) synthesized SWCNTs and (b) SWCNT-COOH.

Table 1. XRD parameters for the raw and acid purified SWCNTs (SWCNT-COOH).

\begin{tabular}{lcc}
\hline $2 \theta$ (degrees) & d-spacings & Intensity \\
\hline Synthesized SWCNTs (not acid treated) & \\
$21.7 ; \mathbf{2 5 . 8} ; 30.3 ;$ & $4.09 ; 3.44 ; 2.95 ; 2.70 ;$ & $2527.1 ; 2610.1 ; 1946.2 ;$ \\
$33.2 ; 35.7 ; 43.4 ; 49.5 ;$ & $2.57 ; 2.09 ;$ & $1275.1 ; 5235.9 ; 1480.7$ \\
$52.5 ; 54.1 ; 57.5$ & $1.83 ; 1.70 ; 1.61$ & $770.0 ; 792.0 ; 920$ \\
& & \\
Acid treated SWCNTs (SWCNT-COOH) & \\
$22.0 ; 25.7,26.0 ; 31.4 ;$ & $4.05 ; 3.46 ; 2.84 ;$ & $3590.6 ; 3160.1 ; 613.6 ;$ \\
$33.1 ; 35.8 ; 43.4 ; 49.5 ;$ & $2.70 ; 2.51 ; 2.09 ;$ & $1097.0 ; 920.6 ; 980.2 ; 389.6 ;$ \\
$52.4 ; 54.0 ; 57.5$ & $1.84 ; 1.74 ; 1.70 ; 160$ & $310 ; 377.21 ; 381.2$
\end{tabular}



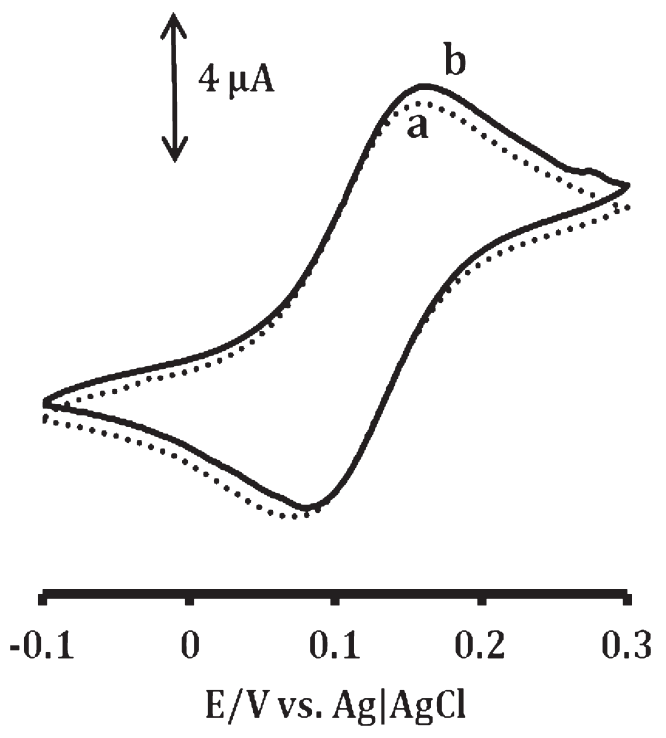

Figure 7. Comparative cyclic voltammogram of $1 \mathrm{mM}$ of $\left[\mathrm{Fe}(\mathrm{CN})_{6}\right]^{3-/ 4-}$ in $0.1 \mathrm{M}$ of $\mathrm{KCl}$ using (a) bare GCE and (b) SWCNT-COOH. Scan rate $=20 \mathrm{mV} / \mathrm{s}$.

cases the D- and the G-bands increased in intensity with functionalization. However, the significant increase in the D-band intensity (42\%) on functionalization is an indication of hybridization from $\mathrm{sp}^{2}$ to $\mathrm{sp}^{3}$ of the sidewall carbon atoms, as has been reported before..$^{28,41}$

\subsection{Electrochemical characterization}

The performance of SWCNT-COOH was evaluated by studying parameters such as peak separations $\left(\Delta E_{\mathrm{p}}\right)$, overpotentials and peak currents of electroactive species. The electrocatalytic behaviour of SWCNT$\mathrm{COOH}$ was evaluated against the bare electrode. It has been reported that the use of CNTs improves the reversibility of redox processes ${ }^{54,55}$ by providing many active sites. Figure 7 shows the cyclic voltammograms of the $\left[\mathrm{Fe}(\mathrm{CN})_{6}\right]^{3-/ 4-}$ redox probe on bare GCE and SWCNT-COOH modified GCE. The SWCNT-COOHGCE gave a peak-to-peak separation of $60 \mathrm{mV}$ versus $70 \mathrm{mV}$ for the bare electrode (at a scan rate of $20 \mathrm{mV} / \mathrm{s}$ ), showing that the SWCNT-COOH modified electrode has better electron transfer properties.

\section{Conclusion}

The use of the compression technique employed in this work to activate the phthalocyanine proved to be a very effective and rapid method for the synthesis of SWCNTs. TEM proved to be useful in ascertaining the successful synthesis of SWCNTs. XRD, UV-vis, FTIR, Raman, TGA and cyclic voltammetry were also used to characterize the synthesized SWCNTs. Based on the different CNT diameters observed in the synthesized SWCNTs, the conditions necessary for the control of the diameter of CNTs is still a major challenge.

\section{Acknowledgements}

This work was supported by the Department of Science and Technology (DST) and National Research Foundation (NRF) of South Africa through DST/NRF South African Research Chairs Initiative for Professor of Medicinal Chemistry and Nanotechnology, Rhodes University and Midlands State University.

\section{References}

1. Iijima S and Ichihashi T 1993 Nature $\mathbf{3 6 3} 603$

2. Bethune D S, Klang C H, de Vries M S, Gorman G, Savoy R, Vazquez J and Beyers R 1993 Nature 363605

3. Oberlin A, Endo M and Koyama T 1976 J. Cryst. Growth 32335

4. Thess A, Lee R, Nikolaev P, Dai H, Petit P, Robert J, Xu C, Lee Y H, Kim S G, Rinzler A G, Colbert D T, Scuseria G E, Tomanek D, Fischer J E and Smalley R E 1996 Science 273483

5. Huang S, Dai L and Mau A W H 1999 J. Phys. Chem. B 1034223

6. Li D C, Dai L, Huang S, Mau A W H and Wang Z L 2000 Chem. Phys. Lett. 316349

7. Huang S and Dai L 2002 J. Phys. Chem. B 1063543

8. Chen Y and Yu J 2005 Carbon 433181

9. Amelinckx S, Zhang X B, Bernaerts D, Zhang X F, Ivanov V and Nagy J B 1994 Science 265635

10. Cantoro M, Hofmann S, Pisana S, Scardaci V, Parvez A, Ducati C, Ferrari A C, Balckburn A M, Wang K Y and Robertson J 2006 Nano Lett. 61107

11. Maruyama S, Kojima R, Miyauchi Y, Chiashi S and Kohno M 2002 Chem. Phys. Lett. 360229

12. Zhu J, Yudasaka M and Iijima S 2003 Chem. Phys. Lett. 380496

13. Hou P-X, Liu C and Cheng H-M 2008 Carbon 462003

14. Shanov V, Yun Y-H and Schulz M J 2006 J. Univ. Chem. Tech. Met. 41377

15. Guo T, Nikolaev P, Rinzler A G, Tomanek D, Colbert D T and Smalley R E 1995 Chem. Phys. Lett. 9910694

16. Liu B C, Lee T J, Lee S H, Park C Y and Lee C J 2003 Chem. Phys. Lett. 37755

17. Li D-C, Dai L, Huang S, Mau A W H and Wang Z L 2000 Phys. Lett. 316349

18. Deepak F L, Govindaraj A and Rao C N R 2001 Chem. Phys. Lett. 3455

19. Araki H, Katayama T and Yoshino K 2001 Appl. Phys. Lett. 792636

20. Katayama T, Araki H and Yoshino K 2002 J. Appl. Phys. 196675

21. Harutyunyan A R, Chen G and Eklund P C 2003 App. Phys. Lett. 824794

22. Chen Y and Chadderton L T 2004 J. Mater. Res. 192791

23. Chen Y, Conway M J and Fitz Gerald J D 2003 Appl. Phys. A 76633

24. Chen Y, Fitz Gerald J D, Chadderton L T and Chaffron L 1999 Mater. Sci. Forum 312-314 375 
25. Seoudi R, El-Bahy G S and El Sayed Z A 2005 J. Mol. Struct. $\mathbf{7 5 3} 119$

26. Jewur S S and Kuriacose J C 1977 Thermochim. Acta 19 195

27. Delamarche E, Bernard A, Schmid H, Michel B and Biebuyck H 1997 Science 276779

28. Ellison M D and Gasda P J 2008 J. Phys. Chem. C 112 738

29. Hudson A and Whitfield H J 1967 Inorg. Chem 61120

30. Liu J, Rinzler A G, Dai H, Hafner J H, Bradley R K, Boul P J, Lu A, Iverson T, Shelimov K, Huffman C B, Rodriguez-Macias F, Shon Y-S, Lee T R, Colbert D T and Smalley R E 1998 Science 280253

31. Banerjee S, Hemraj-Benny T and Wong S S $2005 \mathrm{Adv}$. Mater. 1717

32. Lehman J H, Terrones M, Mansfield E, Hurst K E and Meunier V 2011 Carbon 492581

33. Musso S, Porro S, Yinante M, Vanzetti L, Ploeger R, Giorcelli M, Possetti B, Trotta F, Pederzolli C and Tagliaferro A 2007 Diamond Relat. Mater. 16 1183

34. Itkis M E, Perea D E, Jung R, Niyogi S and Haddon R C 2005 J. Am. Chem. Soc. 1273439

35. Endo M, Takeuchi K, Hiraoka T, Furuta T, Kasai T, Sun X, Kiang C and Dresselhaus M 1997 J. Phy. Chem. Solids $\mathbf{5 8} 1707$

36. Caplovicova M, Danis T, Buc D, Caplovic L, Janik J and Bello I 2007 Ultramicroscopy 107692

37. Gooding J J, Wibowo R, Liu J, Yang W, Losic D, Orbons S, Mearns F J, Shapter J G and Hibbert D B 2003 J. Am. Chem. Soc. 1259006

38. Ballesteros B, de la Torre G, Ehli C, Rahman G M A, Agullo-Rueda F, Guldi D M and Torres T $2007 \mathrm{~J}$. Am. Chem. Soc. 1295061

39. Ma J, Wang J-N, Tsai C-J, Nussinov R and Ma B 2010 Front. Mater. Sci. China 417
40. Milev A S, Tran N, Kannangara G S K, Wilson M A and Avramov I 2008 J. Phys. Chem. C 1125339

41. Zhang W and Swager T M 2007 J. Am. Chem. Soc 129 7714

42. Georgakilas V, Bourlinos A, Gournis D, Tsoufis T, Trapalis C, Mateo-Alonso A and Prato M $2008 \mathrm{~J}$. Am. Chem. Soc. 1308733

43. Saini R K, Chiang I W, Peng H, Smalley R E, Billups W E, Hauge R H and Margrave J L 2003 J. Am. Chem. Soc. 1253617

44. Peng H, Alemany L B, Margrave J L and Khabashesku V N 2003 J. Am. Chem. Soc. 12515174

45. Osswald S, Havel M and Gogotsi Y 2007 J. Raman Spectrosc. $\mathbf{3 8} 728$

46. Stevens J L, Huang A Y, Peng H, Chiang I W, Khabashesku V N and Margrave J L 2003 Nano Lett. 3 331

47. Mugadza T and Nyokong T 2009 Electrochim. Acta $\mathbf{5 4}$ 6347

48. Hao Z, Liu Q F and Wang J B 2010 J. Composite Mater. 44389

49. Campidelli S, Ballesteros B, Filoramo A, Diaz D, de la Torre G, Torres T, Rahman G M A, Ehli C, Kiessling D, Werner F, Sgobba V, Guldi D M, Cioffi C, Prato M and Bourgoin J P 2008 J. Am. Chem. Soc. 13011503

50. Fujiki M and Tabei H 1988 Langmuir 4320

51. Stamatin I, Morozan A, Dumitru A, Ciupina V, Prodan G, Niewolski J and Figiel H 2007 Physica E 3744

52. Mugadza T and Nyokong T 2010 Electrochim. Acta 55 6049

53. Costa S, Borowiak-Palen E, Kruszyńska M, Bachmatiuk A and Kaleńczuk R J 2008 Mat. Scie. Poland 26433

54. Chen R S, Huang W H, Tong H, Wang Z-L and Cheng J-K 2003 Anal. Chem. 75634

55. Valentini F, Amine A, Orlanducci S, Terranova M L and Palleschi G 2003 Anal. Chem. 755413 